\title{
Vascular Protective Effect of an Ethanol Extract of Camellia japonica Fruit: Endothelium-Dependent Relaxation of Coronary Artery and Reduction of Smooth Muscle Cell Migration
}

\author{
Sin-Hee Park, ${ }^{1}$ Bong-Sup Shim, ${ }^{2}$ Jun-Seong Yoon, ${ }^{1}$ Hyun-Ho Lee, ${ }^{3}$ \\ Hye-Won Lee, ${ }^{1}$ Seok-Bong Yoo, ${ }^{2}$ An-Jin Wi, ${ }^{2}$ Whoa-Shig Park, ${ }^{2}$ Hyun-Jung Kim, ${ }^{1}$ \\ Dong-Wok Kim, ${ }^{3}$ and Min-Ho Oak ${ }^{1}$ \\ ${ }^{1}$ College of Pharmacy and Natural Medicine Research Institute, Mokpo National University, Muan-gun, \\ Jeonnam 58554, Republic of Korea \\ ${ }^{2} J e o n n a m$ Forest Resources Research Institute, Naju, Jeonnam 58213, Republic of Korea \\ ${ }^{3}$ Department of Oriental Medicine Resources, Mokpo National University, Muan-gun, Jeonnam 58554, Republic of Korea
}

Correspondence should be addressed to Min-Ho Oak; mhoak@mokpo.ac.kr

Received 30 June 2015; Accepted 24 August 2015

Academic Editor: Ryuichi Morishita

Copyright $(\odot) 2016$ Sin-Hee Park et al. This is an open access article distributed under the Creative Commons Attribution License, which permits unrestricted use, distribution, and reproduction in any medium, provided the original work is properly cited.

Camellia japonica is a popular garden plant in Asia and widely used as cosmetic sources and traditional medicine. However, the possibility that $C$. japonica affects cardiovascular system remains unclear. The aim of the present study was to evaluate vascular effects of an extract of C. japonica. Vascular reactivity was assessed in organ baths using porcine coronary arteries and inhibition of proliferation and migration were assessed using human vascular smooth muscle cells (VSMCs). All four different parts, leaf, stem, flower, and fruits, caused concentration-dependent relaxations and C. japonica fruit (CJF) extract showed the strongest vasorelaxation and its effect was endothelium dependent. Relaxations to CJF were markedly reduced by inhibitor of endothelial nitric oxide synthase (eNOS) and inhibitor of PI3-kinase, but not affected by inhibitor of cyclooxygenase and endothelium-derived hyperpolarizing factor-mediated response. CJF induced activated a time- and concentration-dependent phosphorylation of eNOS in endothelial cells. Altogether, these studies have demonstrated that CJF is a potent endothelium-dependent vasodilator and this effect was involved in, at least in part, PI3K-eNOS-NO pathway. Moreover, CJF attenuated TNF- $\alpha$ induced proliferation and PDGFBB induced migration of VSMCs. The present findings indicate that CJF could be a valuable candidate of herbal medicine for cardiovascular diseases associated with endothelial dysfunction and atherosclerosis.

\section{Introduction}

Across the world, cardiovascular diseases (CVDs) are the primary cause of deaths. In the past, CVDs were considered to be diseases of developed countries. However, recently, CVDs have become most notable in developing countries and this reflects meaningful global changes in behavior and lifestyle [1]. Endothelial dysfunction is a major pathological condition which is almost associated with a risk marker for cardiovascular diseases such as atherosclerosis [2]. Endothelial cells have a key role in the control of vascular homeostasis in part via the release of potent vasodilators such as nitric oxide (NO) and excessive cell proliferation of vascular smooth muscle cells is a key contributor to the growth of atherosclerotic plaque and restenosis.

Several epidemiological studies have been reported that regular intake of plants-derived food such as tea, cacao, and red wine is associated with a reduced risk of cardiovascular diseases [3-7]. The protective effect has been attributed, at least in part, to their high polyphenol content, which might protect the cardiovascular system by a variety of actions, including the ability to dilate blood vessels by stimulating the 
endothelial formation of NO [8] and to inhibit proliferation and migration of vascular smooth muscle cells $[8,9]$. Taken together, these findings suggest the view that polyphenol-rich natural products may protect the cardiovascular system, in part, by improving the vascular homeostasis, hence, retarding the development of cardiovascular diseases.

In order to identify vasoprotective natural products, we have recently evaluated the cardiovascular protective properties of medicinal plants extracts used in oriental medicine on isolated porcine coronary artery and human vascular smooth muscle cells (VSMCs). These investigations have revealed a strong cardiovascular protective effect of an ethanolic extract of Camellia japonica fruits (CJFs).

Previous studies have shown that $C$. japonica (CJ), extensively distributed in Japan and Korea, possesses various biological activities, including antioxidant activity [10, 11], antimetastasis activity [12], antiallergic responses [13], and antibacterial activity [14]. However, these findings have been studied in oil, flower, or leaf of CJ. As constituents of CJ, saponins in the seeds [15], flavonol glycosides in the leaves [10], and triterpenes, several hydrolyzable tannins, acylated anthocyanins, and purine alkaloids in the flowers [16] have been reported. But the chemical constituents and pharmacological activity of fruits have been reported.

The aim of the present study was to evaluate the vasoprotective effect of an extract of C. japonica fruits on vascular functions, if so, to characterize the underlying mechanism and signaling pathway involved. In particular, we have determined the ability of CJF (1) to cause endotheliumdependent relaxation of porcine coronary artery, (2) to activate endothelial NO synthase by phosphorylation in cultured endothelial cells, and (3) to prevent proliferation and migration of vascular smooth muscle cells induced by growth factors.

\section{Materials and Methods}

2.1. Plant Extract. The C. japonica (CJ) was collected at the southern parts of Korean Peninsula and voucher specimen was deposited at the Herbarium of Jeonnam Forest Resources Research Institute, Korea. Each dried leaf, stem, fruit, and flower was cut into small pieces and ground using a commercial food mixer. The fruits of CJ $(1 \mathrm{Kg})$ were extracted two times with hot $70 \%$ ethanol for 4 hours. This residue was evaporated in vacuo to yield the total extract (93.4 g, $9.32 \% \mathrm{w} / \mathrm{w})$. A solution was prepared with physiological salt solution (PSS) at all concentration of $100-300 \mathrm{mg} / \mathrm{mL}$ on the day of the experiment.

2.2. Vascular Reactivity Study. Vascular reactivity study was performed using porcine coronary arteries as described previously [17]. Briefly, left anterior descending coronary arteries of porcine heart (got from the local slaughterhouse in Mokpo, Korea) were dissected and cleaned of connective tissue and cut into rings (4-5 $\mathrm{mm}$ in length) carefully. Then, rings were suspended in organ baths containing oxygenated $\left(95 \% \mathrm{O}_{2}\right.$ and $5 \% \mathrm{CO}_{2}$ ) Krebs bicarbonate solution (mmol/L: $\mathrm{NaCl}$ 119, $\mathrm{KCl} 4.7, \mathrm{KH}_{2} \mathrm{PO}_{4} 1.18, \mathrm{MgSO}_{4} 1.18, \mathrm{CaCl}_{2} 1.25, \mathrm{NaHCO}_{3}$ 25 , and $\mathrm{D}$-glucose $11, \mathrm{pH} 7.4,37^{\circ} \mathrm{C}$ ) for the determination of changes in isometric tension. Following equilibration for 90 min under a resting tension of $5 \mathrm{~g}$, rings were twice contracted with $\mathrm{KCl}(80 \mathrm{mmol} / \mathrm{L})$. Thereafter, the rings were precontracted with the thromboxane mimetic U46619 (1$60 \mathrm{nmol} / \mathrm{L}$ ) to about $80 \%$ of the maximal contraction and the relaxation to bradykinin $(0.3 \mu \mathrm{mol} / \mathrm{L})$ was determined. After washout and a 30-minute equilibration period, rings were again contracted with U46619 before a concentrationrelaxation curve to plant extract. In some experiments, rings were exposed to an inhibitor for $30 \mathrm{~min}$ before the addition of U46619.

2.3. Cell Culture. Endothelial cells were isolated from porcine left anterior descending coronary arteries by collagenase treatment (type I, Worthington, $1 \mathrm{mg} / \mathrm{mL}$ for $12 \mathrm{~min}$ at $37^{\circ} \mathrm{C}$ ) and cultured in T-flasks containing medium MCDB 131 supplemented with $15 \%$ fetal bovine serum (FBS), penicillin $(100 \mathrm{U} / \mathrm{mL})$, streptomycin $(100 \mathrm{U} / \mathrm{mL})$, fungizone $(250 \mu \mathrm{g} / \mathrm{mL})$, and L-glutamine $(2 \mathrm{mM})$ and grown for $48-$ $72 \mathrm{~h}$. Confluent cultures of cells (first passage) were exposed to serum-free culture medium in the presence of $0.1 \%$ bovine serum albumin for $6 \mathrm{~h}$ prior to treatment. Vascular smooth muscle cells (VSMCs) were purchased from Bio-Whittaker (San Diego, CA) and cultured in MCDB131 with 10\% FBS and antibiotics. For all experiments, early passages of VSMCs were grown to $80-90 \%$ confluence. In a typical experiment, the cells were starved in serum-free culture medium containing $0.1 \%$ bovine serum albumin for $24 \mathrm{~h}$.

2.4. Determination of the Phosphorylation Level of eNOS. Endothelial cells were lysed in extraction buffer. Total proteins $(10 \mu \mathrm{g})$ were separated on SDS-polyacrylamide gels at $100 \mathrm{~V}$ for $2 \mathrm{~h}$. Separated proteins were transferred onto polyvinylidene difluoride membranes at $100 \mathrm{~V}$ for $2 \mathrm{~h}$. Membranes were blocked with bovine serum albumin for $1 \mathrm{~h}$. Membranes were incubated with a primary antibody, $\mathrm{p}$ eNOS Ser1177 from rabbit. After washing, membranes were incubated with the appropriate horseradish peroxidaseconjugated secondary antibody. The blots were then washed 5-6 times in TBST and developed using an enhanced chemiluminescence (ECL) detection kit.

2.5. Proliferation Assay. VSMCs proliferation was assessed by using MTT assay. VSMCs seeded in 96-well plates were pretreated with CJF for $1 \mathrm{~h}$ prior to stimulation of the cells with TNF- $\alpha(100 \mu \mathrm{g} / \mathrm{mL})$ for additional $24 \mathrm{~h}$. Then, MTT solution was added for $4 \mathrm{~h}$ followed by solubilization of formazan crystals in dimethyl sulfoxide (DMSO). The purple color thus formed was measured at $540 \mathrm{~nm}$.

2.6. Cell Migration Assay. VSMCs were assessed in wound healing scratch assays using the IncuCyte (Essen Bioscience). Briefly, $4 \times 10^{5}$ cells were plated on the 96-well ImageLock plates (Essen BioScience, catalog number 4379) and incubated in the complete media until confluent monolayer forms. Wounds were made using the 96-pin WoundMaker (Essen BioScience) and incubated with MCDB131 containing $0.1 \%$ BSA and PDGF-BB $(20 \mathrm{ng} / \mathrm{mL})$ with or without increasing concentrations of CJF. Cell migration was monitored in 


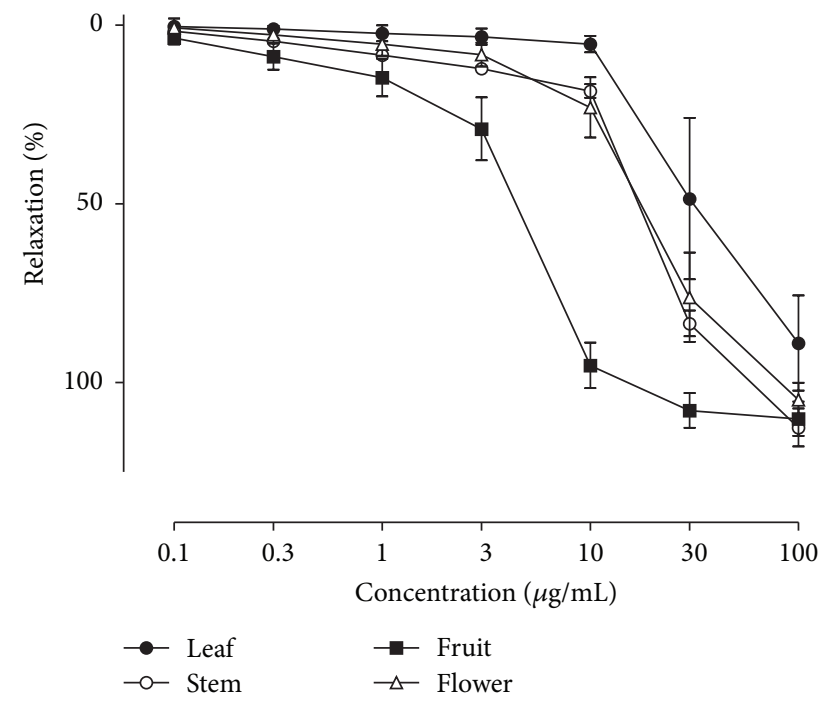

FIGURE 1: Extracts from several different parts of C. japonica cause endothelium-dependent relaxations in the porcine coronary artery. Arterial rings with endothelium were contracted with U46619 before the addition of increasing concentrations of either leaf, stem, fruit, or flower of $C$. japonica. The relaxation response is expressed as the percentage relaxation of the U46619-induced contraction. Results are shown as means $\pm \operatorname{SEM}(n=6)$.

real time by IncuCyte, and confluence was measured by the IncuCyte software.

2.7. Statistical Analysis. Values are expressed as means \pm SEM. Statistical evaluation was performed with Student's $t$ test for paired data or ANOVA followed by Fisher's protected least significant difference test where appropriate. $\mathrm{ED}_{50}$ is defined as the concentration of CJ extracts causing $50 \%$ relaxation. Values of $P<0.05$ were considered statistically significant.

\section{Results}

3.1. CJF Induces Endothelium-Dependent Relaxation in Porcine Coronary Arteries. CJ extracts from four different parts, leaf, stem, fruit, and flower, were evaluated for their potency of concentration-dependent relaxations of porcine coronary artery rings (Figure 1). All four different parts caused concentration-dependent relaxations and C. japonica fruit extract (CJF) is the most active one. The $\mathrm{ED}_{50}$ value of the vasorelaxing effect of leaf, stem, flower, and fruit extracts was $88.70 \pm 2.29 \mu \mathrm{g} / \mathrm{mL}, 38.24 \pm 1.31 \mu \mathrm{g} / \mathrm{mL}$, $33.89 \pm 1.39 \mu \mathrm{g} / \mathrm{mL}$, and $5.37 \pm 1.33 \mu \mathrm{g} / \mathrm{mL}$, respectively. Although CJF caused full relaxations in porcine coronary artery rings with endothelium, no such effect was observed in those without endothelium indicating that CJF induced endothelium-dependent vasorelaxations (Figures 2(a) and 2(b)). Next, the possibility that CJF, besides inducing endothelium-dependent relaxations, also affects contractile responses was assessed. Exposure of porcine coronary artery rings to CJF concentration-dependently reduced contractile responses to thromboxane mimetic U46619 in rings (Figure 2(c)).

3.2. CJF Induces Endothelium-Dependent NO-Medicated Relaxation via the Redox-Sensitive PI3-Kinase Pathway. Since previous investigations have shown that plants-derived polyphenols induce the redox-sensitive PI3-kinase/Aktdependent activation of endothelial NO synthase to cause vasorelaxation [18], the role of this pathway in the CJFinduced relaxation was determined. Further characterization of the endothelium-dependent relaxation was done with CJF. Relaxations to CJF in rings with endothelium were markedly reduced by $\mathrm{N}^{\omega}$-nitro-L-arginine (L-NA, endothelial nitric oxide synthase inhibitor) but not minimally modified by indomethacin (an inhibitor of cyclooxygenases) and the combination of charybdotoxin plus apamin (inhibitors of EDHFmediated responses, Figures 3(a) and 3(b)). In addition, the combination of L-NA plus charybdotoxin and apamin abolished relaxations to CJF, suggesting the involvement of NOmediated component and also, to some extent, an EDHFmediated component (Figure 3(a)). Relaxations to CJF also strongly reduced by the PI3-kinase inhibitor, wortmannin (Figure 3(c)).

3.3. CJF Induces the Phosphorylation of eNOS at Ser1177 in Endothelial Cells. To better characterize the signaling pathway involved in eNOS activation in response to CJF, level of phosphorylated eNOS was assessed in endothelial cells by immunoblotting. Unstimulated endothelial cells had either no or only a low level of phosphorylated eNOS at ser1177. CJF (1-100 $\mu \mathrm{g} / \mathrm{mL}, 10 \mathrm{~min})$ evoked the concentration-dependent phosphorylation of eNOS at ser1177 in endothelial cells (Figure 4(a)). Exposure of endothelial cells to CJF $(30 \mu \mathrm{g} / \mathrm{mL})$ caused the progressive appearance of strong phosphorylation signal of eNOS up to 60 min (Figures 4(a) and 4(b)).

3.4. CJF Inhibits VSMC Proliferation and Migration. To characterize cardiovascular protective effect of CJF, we have performed experiments whether CJF inhibits proliferation and migration of VSMCs. Stimulation of VSMCs with TNF- $\alpha$ induced proliferation and the treatment of CJF concentration-dependently inhibited VSMCs proliferation induced by TNF- $\alpha$ (Figure 5(a)). CJF at concentrations 50, 100,200 , and $400 \mu \mathrm{g} / \mathrm{mL}$ significantly reduced the proliferation rate to $77.85 \%, 70.12 \%, 61.93 \%$, and $56.33 \%$ of the control (TNF- $\alpha$ treated without CJF), respectively. To confirm that the inhibitory effects were not due to toxicity or damage to the cells, various concentrations of CJF were treated in nonstimulated cells for $24 \mathrm{~h}$. CJF had no effect on the basal level of cell viability (Figure 5(b)).

The effects of CJF on VSMCs migration as evaluated by using a wound healing assay are as shown in Figure 6. CJF concentration-dependently suppressed PDGF-BB induced VSMCs wound healing for 24 and $48 \mathrm{~h}$ after injury (Figure $6(\mathrm{~b}))$. CJF at 10,30 , and $100 \mu \mathrm{g} / \mathrm{mL}$ showed the significant inhibition of healing $(22.28 \%, 14.38 \%$, and $4.3 \%$ compared with control, resp.) at $48 \mathrm{~h}$. 


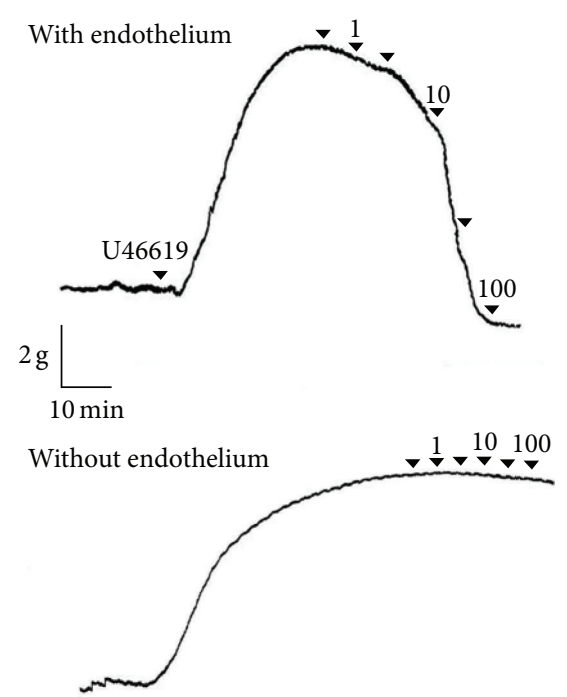

(a)

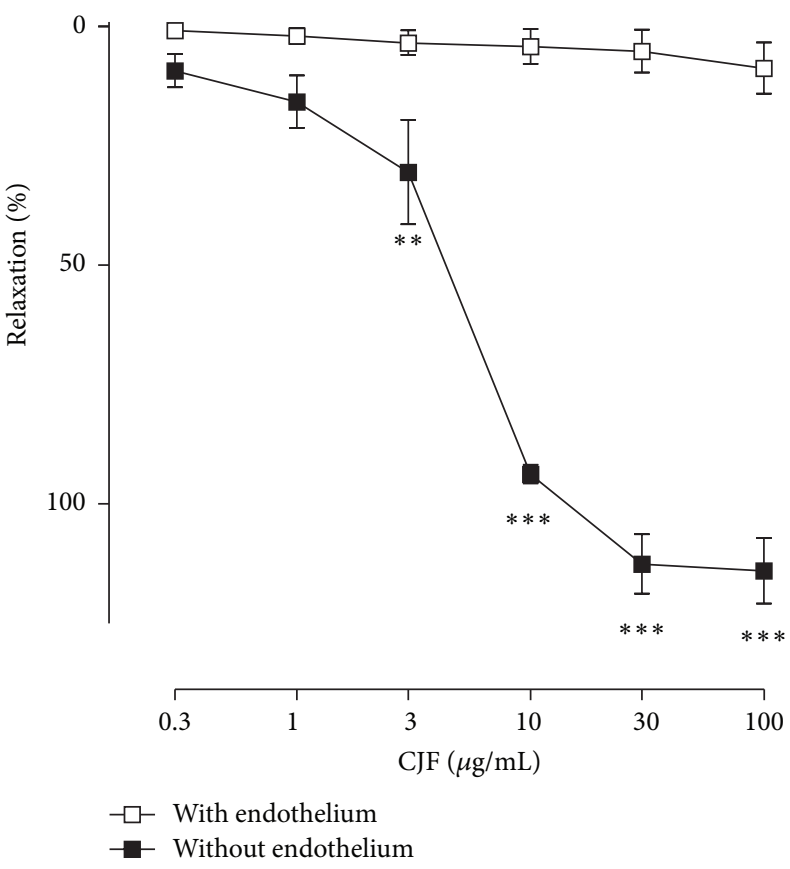

(b)

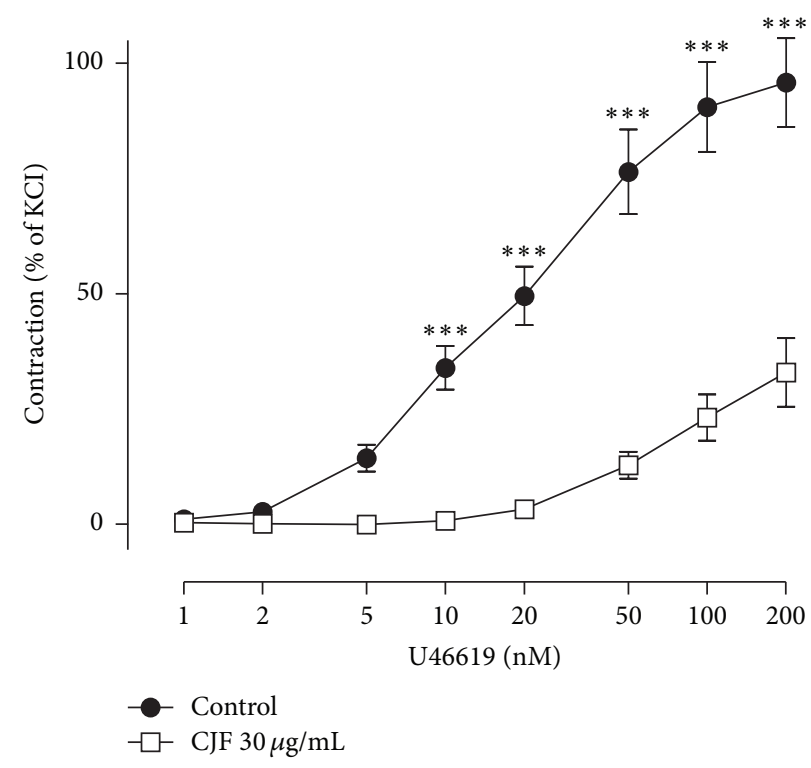

(c)

FIGURE 2: Characterization of endothelium-dependent relaxations to CJF in porcine coronary artery rings. Representative original tracing (a), corresponding cumulative data (b). The relaxation response is expressed as the percentage relaxation of the U46619-induced contraction. Effect of CJF on contractile responses (c). As indicated, intact rings were exposed to CJF $(30 \mu \mathrm{g} / \mathrm{mL}) 30 \mathrm{~min}$ before the addition of increasing concentrations of U46619. Results are shown as means \pm SEM $(n=7) .{ }^{*} P<0.05,{ }^{* *} P<0.01,{ }^{* * *} P<0.001$, significant difference versus rings without endothelium (b) or control (c).

\section{Discussion}

Cardiovascular diseases (CVDs) such as atherosclerosis are associated with endothelial dysfunction, and these CVDs risk factor modification leads to improvement in vascular function. Endothelial dysfunction is a pathological condition, mostly characterized by an imbalance between vasodilator and vasoconstrictor substances, and this imbalance leads to an impairment of endothelium-dependent relaxation, which appears the functional characteristic of endothelial dysfunction. Endothelial cells lining the luminal surface of all blood vessels have a vital role in the control of vascular tone partially via the release of powerful vasodilators including nitric oxide (NO) and endothelium-derived hyperpolarizing factor 


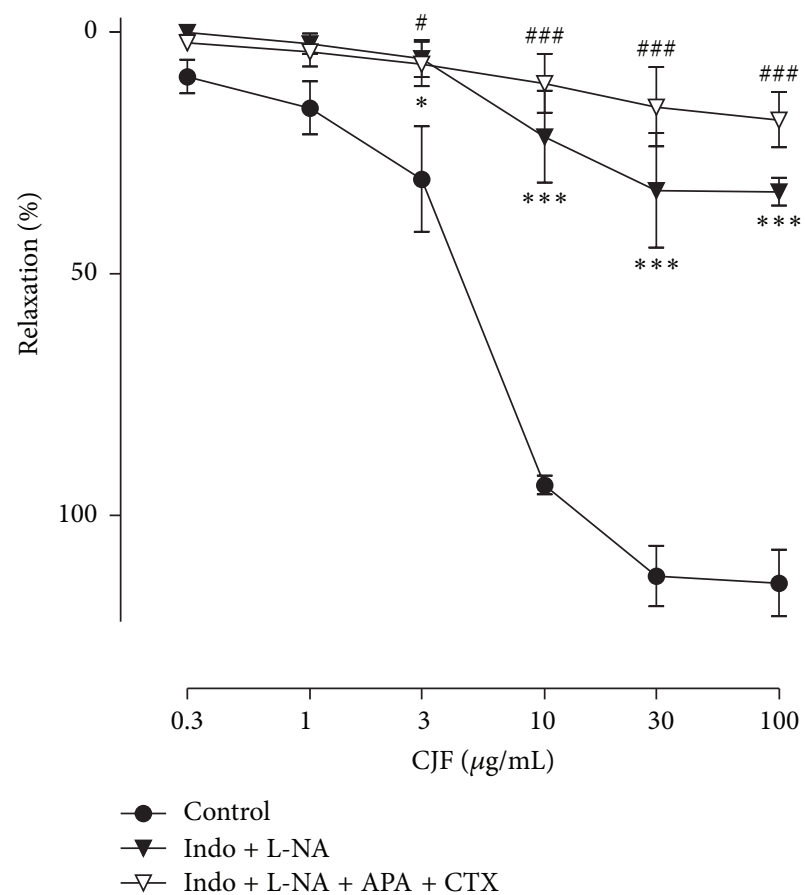

(a)
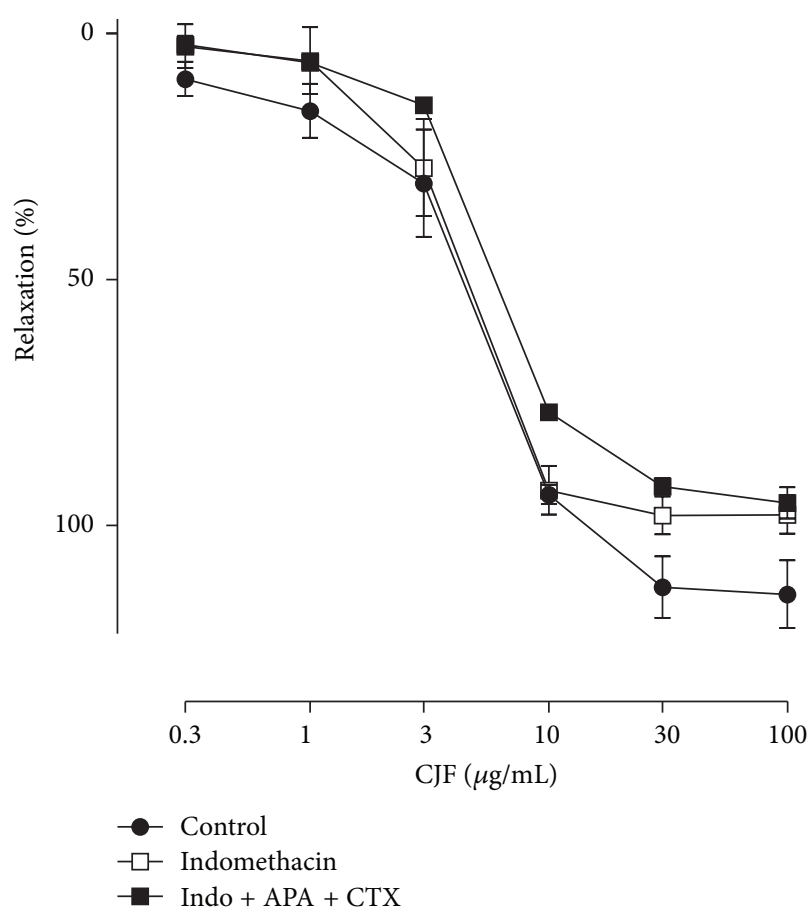

(b)

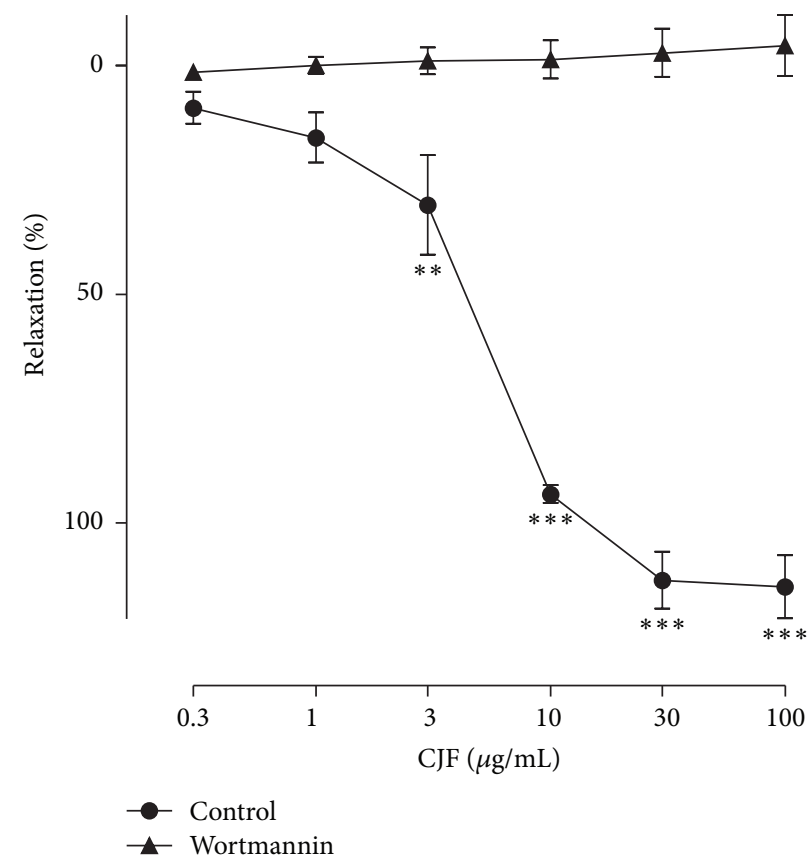

(c)

FIGURE 3: Characterization of endothelium-dependent relaxations to CJF in porcine coronary artery rings. Rings with endothelium were incubated with either indomethacin $(10 \mu \mathrm{M}), \mathrm{N}^{\omega}$-nitro-L-arginine (L-NA, $\left.10 \mu \mathrm{M}\right)$, charybdotoxin $(\mathrm{CTX}, 100 \mathrm{nM})$ plus apamin $(\mathrm{APA}, 100 \mathrm{nM})$, or the PI3-kinase inhibitors wortmannin $(30 \mathrm{nM})$ for $30 \mathrm{~min}$ before the contraction to U46619 and subsequent relaxation to CJF. The relaxation response is expressed as the percentage relaxation of the U46619-induced contraction. Results are shown as means \pm SEM $(n=5)$. ${ }^{*} P<0.05$, ${ }^{* *} P<0.01,{ }^{* * *} P<0.001$, significant difference versus control. 


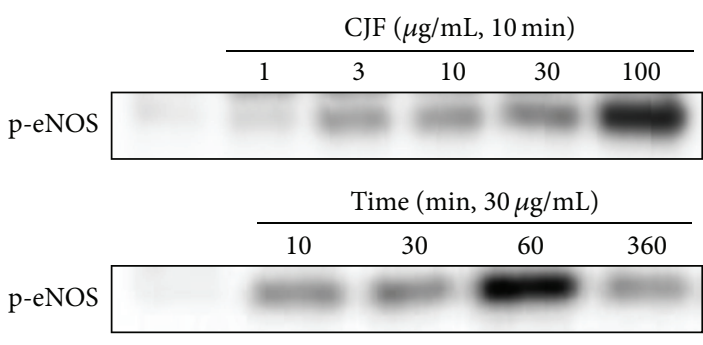

(a)

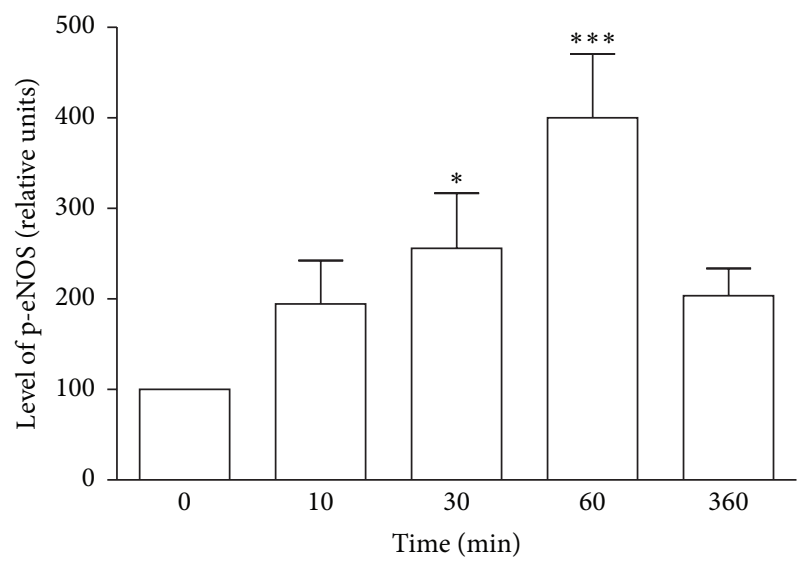

(b)

FIGURE 4: CJF induces a concentration- and time-dependent phosphorylation of eNOS at Ser1177 in endothelial cells. Cells were exposed to CJF for the indicated concentrations and times at $37^{\circ} \mathrm{C}$. Thereafter, the level of p-eNOS was determined by Western blot analysis. (a) Representative immunoblots and (b) corresponding cumulative data for time-dependent phosphorylation of eNOS. Results are shown as means \pm SEM $(n=3-4) .{ }^{*} P<0.05,{ }^{* *} P<0.01,{ }^{* * *} P<0.001$, significant difference versus control.

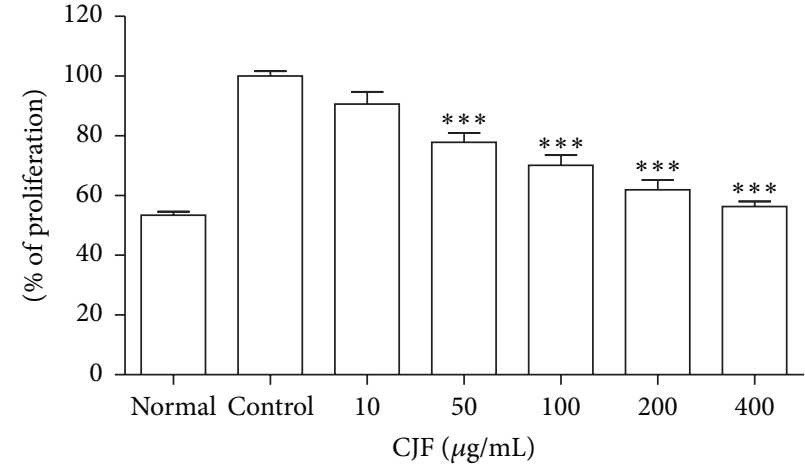

(a)

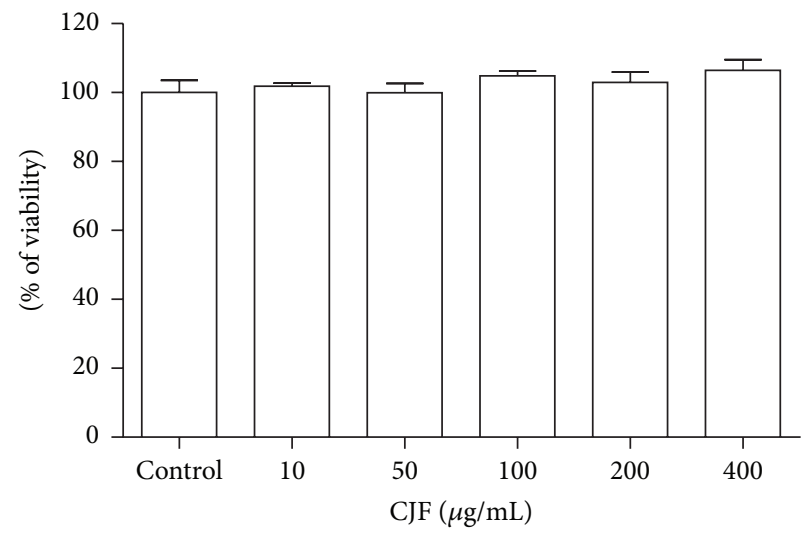

(b)

FIgURE 5: (a) Serum starved VSMCs were pretreated with indicated concentrations of CJF followed by stimulation with TNF- $\alpha$ (100 $\mu$ g/mL) for $24 \mathrm{~h}$. Cell proliferation was measured by MTT assay and values are expressed as means $\pm \operatorname{SEM}(n=5) .{ }^{*} P<0.05,{ }^{* *} P<0.01$, ${ }^{* * *} P<0.001$, significant difference versus control. (b) Serum starved VSMCs were treated with indicated concentrations of CJF without stimulation for $24 \mathrm{~h}$. Cell viability was measured by MTT assay. Results are shown as means $\pm \operatorname{SEM}(n=5) .{ }^{*} P<0.05$, significant difference versus control.

(EDHF). Particularly, the endothelium-dependent relaxation was involved in increased guanosine $3^{\prime}, 5^{\prime}$-cyclic monophosphate (cyclic GMP) levels in the intact aorta and both the relaxation and the increase in cyclic GMP were blocked by an inhibition of eNOS synthase [19]. In addition, NO inhibits other major events in the development of atherosclerosis such as platelet aggregation and smooth muscle cell proliferation $[2,20]$. Especially in the microcirculation, prostacyclin and endothelial-derived hyperpolarization factors (EDHF) also play a key role [21].

Among the several different parts of C. japonica (CJ) investigated in present study, the most active one was predominantly fruit of CJ. The present investigations indicate that CJF is a potent endothelium-dependent vasodilator of coronary arteries and that this activity involves several elements. Endothelium-dependent relaxations to CJF were markedly inhibited by L-NA, an endothelial NO synthase inhibition. In contrast, these relaxations were not affected by indomethacin and the combination of charybdotoxin plus apamin, ruling out the involvement of vasoactive prostanoids and EDHF. In addition to inducing relaxation, CJF also significantly blunted contractile response to vasoconstrictors such as thromboxane analogue, U46619. Since no such effects are observed in rings without endothelium and the beneficial effect of the endothelium is abolished by $\mathrm{N}^{\omega}$ nitro-L-arginine, the blunted contractile responses are most likely due to the ability of CJF to stimulate the endothelial formation of NO.

Previous studies have indicated that the PI3-kinase pathway mediates the increases of eNOS activation and $\mathrm{NO}$ formation in response to several stimuli, including shear stress, and polyphenols through the PI3K-Akt-dependent 


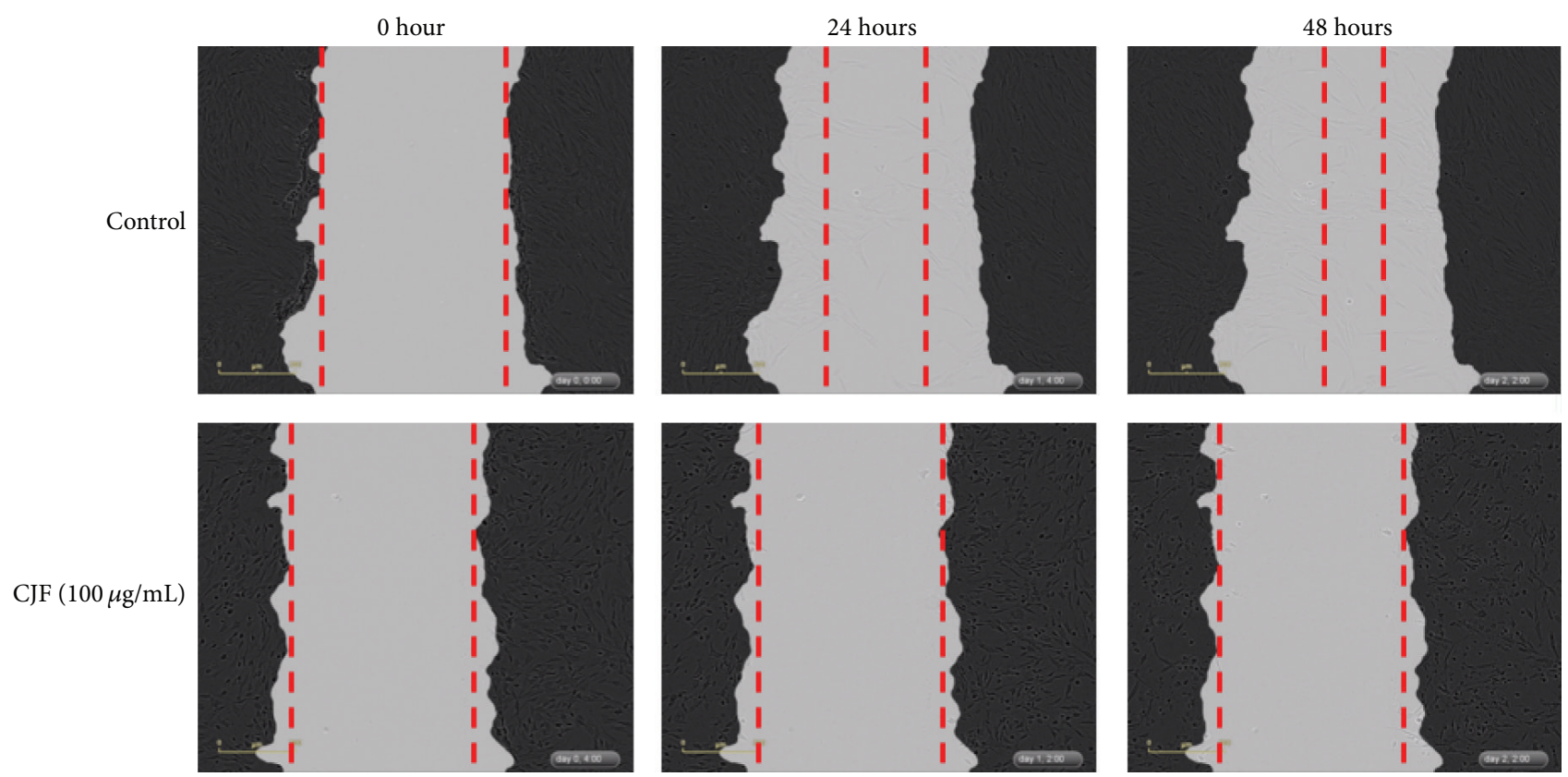

(a)

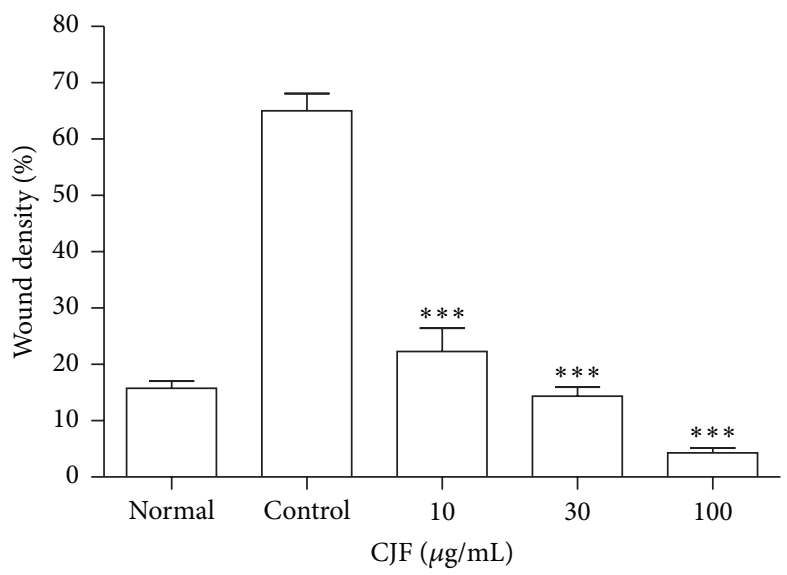

(b)

FIGURE 6: (a) Confluent VSMCs were gently removed using the 96-pin WoundMaker to induce reproducible wounds and then the cells were treated with CJF for $1 \mathrm{~h}$ followed by PDGF-BB treatment. Images of wounded area were captured immediately (time 0 ) and 24 and $48 \mathrm{~h}$ after injury. (b) Finally, wound density was quantified as percentage of initial wound area that had been recovered with VSMCs. Results are shown as means $\pm \operatorname{SEM}(n=5) .{ }^{*} P<0.05,{ }^{* *} P<0.01,{ }^{* * *} P<0.001$, significant difference versus control (PDGF-BB alone).

phosphorylation of eNOS at Ser1177, resulting in an increased formation of NO and vasorelaxation [18, 22]. Indeed, our findings indicated a rapid increase of phosphorylation of eNOS at Ser1177 in concentration-dependent and timedependent manner in endothelial cells. Moreover, inhibition of PI3-kinase pathway by wortmannin blocked the CJFinduced coronary artery relaxation. Altogether, the present findings indicate that CJF causes powerful endotheliumdependent relaxations involving, at least in part, PI3-kinaseeNOS-NO pathway.

Additionally, we performed other experiments under a different aspect. Since VSMCs proliferation and migration are one of the leading factors in the progression of atherosclerosis [23], inhibition of VSMCs proliferation and migration represents a critical therapeutic strategy for the prevention of atherosclerosis. Various growth factors including PDGF$\mathrm{BB}$ and TNF- $\alpha$ are upregulated in atherosclerosis [24, 25]. In our in vitro model of VSMCs proliferation, the treatment of CJF concentration-dependently inhibited TNF- $\alpha$ induced VSMCs proliferation. At least, VSMCs migration would require a chemoattractant to direct their movement toward the intima, the ability to breach and transverse the ECM barriers, and the activation of the cellular machinery for cell movement in response to the chemoattractant [26]. Our studies used PDGF-BB as a chemoattractant, since considerable evidence supports a role of PDGF-BB in VSMCs migration. CJF strongly inhibited PDGF-BB induced VSMCs migration. 
Camellia japonica ("Dongbaek" in Korean) is a popular garden plant in Korea. In addition, flower, seed, and leaves are widely used as cosmetic sources and traditional medicine. Previous study revealed that extracts from different parts of C. japonica have various biological activities such as antioxidant activity [10, 11], antimetastasis activity [12], antiallergic responses [13], and antibacterial activity [14]. However, these biological activities are focused on seeds, flowers, and leaves, not fruits. Until now, the activities of fruit from C. japonica have drawn much less attention than those of other parts from C. japonica. The present findings indicated that fruit from $C$. japonica has strong cardiovascular protection effects and could be a good candidate of natural medicines for prevention and treatment of cardiovascular diseases. Despite these beneficial effects from fruit, very little information regarding its constituents was not available to compare with seed and leaves from C. japonica. Very recently, Uddin et al. isolated oleanane-type triterpenes from fruit peels of $C$. japonica as protein tyrosine phosphatase $1 \mathrm{~B}$ inhibitors [27]. The vasoprotective active compounds from CJF have not been identified yet due to the lack of constituents' study; therefore, we will undertake further study to identify active compounds and their underlying molecular mechanisms.

\section{Conclusions}

The present studies indicate that Camellia japonica fruit (CJF) extract is a potent endothelium-dependent vasodilator by inducing the endothelial formation of NO via PI3-kinase pathway in endothelial cells. In addition, CJF attenuated TNF- $\alpha$ induced VSMCs proliferation and PDGF-BB induced VSMCs migration. They further suggest that CJF could be a valuable candidate of herbal medicine for cardiovascular diseases associated with endothelial dysfunction and atherosclerosis.

\section{Conflict of Interests}

The authors declare that there is no conflict of interests regarding the publication of this paper.

\section{References}

[1] C. Institute of Medicine Committee on Preventing the Global Epidemic of Cardiovascular Disease: Meeting the Challenges in Developing, "The National Academies collection: reports funded by National Institutes of health," in Promoting Cardiovascular Health in the Developing World: A Critical Challenge to Achieve Global Health, V. Fuster and B. B. Kelly, Eds., National Academies Press (US) National Academy of Sciences, Washington, DC, USA, 2010.

[2] A. J. Flammer, T. Anderson, D. S. Celermajer et al., "The assessment of endothelial function: from research into clinical practice," Circulation, vol. 126, no. 6, pp. 753-767, 2012.

[3] A. Di Castelnuovo, S. Rotondo, L. Iacoviello, M. B. Donati, and G. De Gaetano, "Meta-analysis of wine and beer consumption in relation to vascular risk," Circulation, vol. 105, no. 24, pp. 28362844, 2002.
[4] S. Renaud and M. de Lorgeril, "Wine, alcohol, platelets, and the French paradox for coronary heart disease," The Lancet, vol. 339, no. 8808, pp. 1523-1526, 1992.

[5] I. C. W. Arts, P. C. H. Hollman, E. J. M. Feskens, H. B. Bueno de Mesquita, and D. Kromhout, "Catechin intake might explain the inverse relation between tea consumption and ischemic heart disease: The Zutphen Elderly study," American Journal of Clinical Nutrition, vol. 74, no. 2, pp. 227-232, 2001.

[6] I. C. W. Arts, D. R. Jacobs Jr., L. J. Harnack, M. Gross, and A. R. Folsom, "Dietary catechins in relation to coronary heart disease death among postmenopausal women," Epidemiology, vol. 12, no. 6, pp. 668-675, 2001.

[7] S. Kuriyama, T. Shimazu, K. Ohmori et al., "Green tea consumption and mortality due to cardiovascular disease, cancer, and all causes in Japan: the Ohsaki study," Journal of the American Medical Association, vol. 296, no. 10, pp. 1255-1265, 2006.

[8] J.-C. Stoclet, T. Chataigneau, M. Ndiaye et al., "Vascular protection by dietary polyphenols," European Journal of Pharmacology, vol. 500, no. 1-3, pp. 299-313, 2004.

[9] M.-H. Oak, J. El Bedoui, P. Anglard, and V. B. Schini-Kerth, "Red wine polyphenolic compounds strongly inhibit promatrix metalloproteinase-2 expression and its activation in response to thrombin via direct inhibition of membrane type 1-matrix metalloproteinase in vascular smooth muscle cells," Circulation, vol. 110, no. 13, pp. 1861-1867, 2004.

[10] K.-I. Onodera, K. Hanashiro, and T. Yasumoto, "Camellianoside, a novel antioxidant glycoside from the leaves of Camellia japonica," Bioscience, Biotechnology and Biochemistry, vol. 70, no. 8, pp. 1995-1998, 2006.

[11] M. J. I. Piao, E. S. O. Yoo, Y. S. A. Koh et al., "Antioxidant effects of the ethanol extract from flower of Camellia japonica via scavenging of reactive oxygen species and induction of antioxidant enzymes," International journal of molecular sciences, vol. 12, no. 4, pp. 2618-2630, 2011.

[12] D. Miura, Y. Kida, and H. Nojima, "Camellia oil and its distillate fractions effectively inhibit the spontaneous metastasis of mouse melanoma BL6 cells," FEBS Letters, vol. 581, no. 13, pp. 2541-2548, 2007.

[13] J.-H. Lee, J.-W. Kim, N.-Y. Ko et al., "Camellia japonica suppresses immunoglobulin E-mediated allergic response by the inhibition of Syk kinase activation in mast cells," Clinical and Experimental Allergy, vol. 38, no. 5, pp. 794-804, 2008.

[14] K. Y. Kim, P. M. Davidson, and H. J. Chung, "Antibacterial activity in extracts of Camellia japonica L. petals and its application to a model food system," Journal of Food Protection, vol. 64, no. 8, pp. 1255-1260, 2001.

[15] M. Yoshikawa, E. Harada, T. Murakami, H. Matsuda, J. Yamahara, and N. Murakami, "Camelliasaponins B1, B2, C1 and C2, new type inhibitors of ethanol absorption in rats from the seeds of Camellia japonica L," Chemical and Pharmaceutical Bulletin, vol. 42, no. 3, pp. 742-744, 1994.

[16] H. Nakajima, H. Itokawa, and A. Ikuta, "Studies on the constituents of the flower of Camellia japonica (2)," Yakugaku Zasshi, vol. 104, no. 2, pp. 157-161, 1984.

[17] E. Anselm, M. Chataigneau, M. Ndiaye, T. Chataigneau, and V. B. Schini-Kerth, "Grape juice causes endothelium-dependent relaxation via a redox-sensitive Src- and Akt-dependent activation of eNOS," Cardiovascular Research, vol. 73, no. 2, pp. 404413, 2007.

[18] M. Ndiaye, M. Chataigneau, I. Lobysheva, T. Chataigneau, and V. B. Schini-Kerth, "Red wine polyphenol-induced, endothelium-dependent $\mathrm{NO}$-mediated relaxation is due to the 
redox-sensitive PI3-kinase/Akt-dependent phosphorylation of endothelial NO-synthase in the isolated porcine coronary artery," The FASEB Journal, vol. 19, no. 3, pp. 455-457, 2005.

[19] D. F. Fitzpatrick, S. L. Hirschfield, and R. G. Coffey, "Endothelium-dependent vasorelaxing activity of wine and other grape products," The American Journal of Physiology-Heart and Circulatory Physiology, vol. 265, no. 2, part 2, pp. H774$\mathrm{H} 778,1993$.

[20] M. Feletou and P. M. Vanhoutte, "Endothelial dysfunction: a multifaceted disorder (The Wiggers Award Lecture)," The American Journal of Physiology-Heart and Circulatory Physiology, vol. 291, no. 3, pp. H985-H1002, 2006.

[21] G. Edwards, M. Félétou, and A. H. Weston, "Endotheliumderived hyperpolarising factors and associated pathways: a synopsis," Pflügers Archiv-European Journal of Physiology, vol. 459, no. 6, pp. 863-879, 2010.

[22] S. Dimmeler, I. Fleming, B. Fisslthaler, C. Hermann, R. Busse, and A. M. Zeiher, "Activation of nitric oxide synthase in endothelial cells by Akt-dependent phosphorylation," Nature, vol. 399, no. 6736, pp. 601-605, 1999.

[23] R. Ross, "The pathogenesis of atherosclerosis: a perspective for the 1990s," Nature, vol. 362, no. 6423, pp. 801-809, 1993.

[24] P. S. Monraats, N. M. M. Pires, A. Schepers et al., "Tumor necrosis factor-alpha plays an important role in restenosis development," The FASEB Journal, vol. 19, no. 14, pp. 1998-2004, 2005.

[25] S. Tanizawa, M. Ueda, C. M. van der Loos, A. C. van der Wal, and A. E. Becker, "Expression of platelet derived growth factor $\mathrm{B}$ chain and beta receptor in human coronary arteries after percutaneous transluminal coronary angioplasty: an immunohistochemical study," Heart, vol. 75, no. 6, pp. 549-556, 1996.

[26] R. R. Pauly, A. Passaniti, C. Bilato et al., "Migration of cultured vascular smooth muscle cells through a basement membrane barrier requires type IV collagenase activity and is inhibited by cellular differentiation," Circulation Research, vol. 75, no. 1, pp. 41-54, 1994.

[27] M. N. Uddin, G. Sharma, J.-L. Yang et al., "Oleanane triterpenes as protein tyrosine phosphatase $1 \mathrm{~B}$ (PTP1B) inhibitors from Camellia japonica," Phytochemistry, vol. 103, pp. 99-106, 2014. 


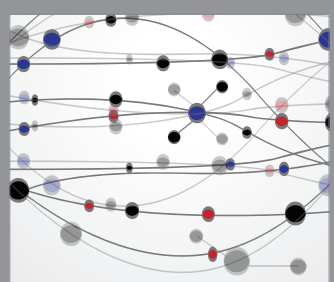

The Scientific World Journal
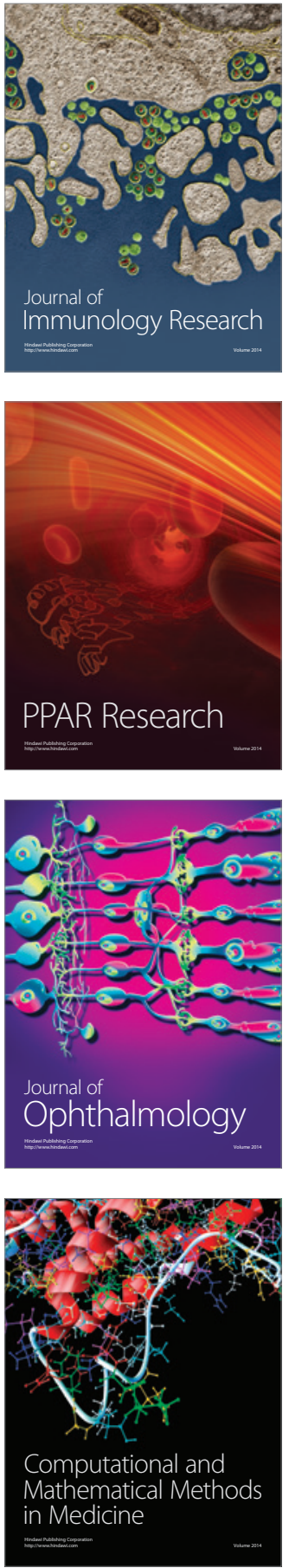

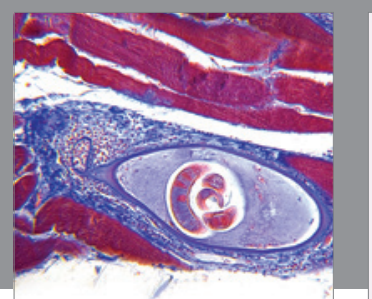

Gastroenterology Research and Practice

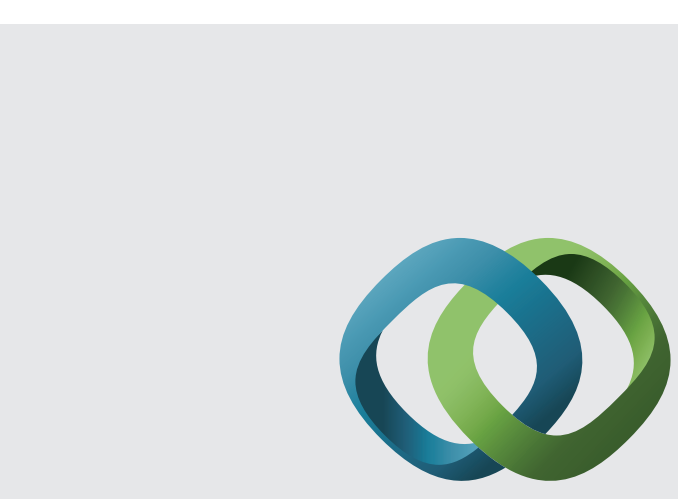

\section{Hindawi}

Submit your manuscripts at

http://www.hindawi.com
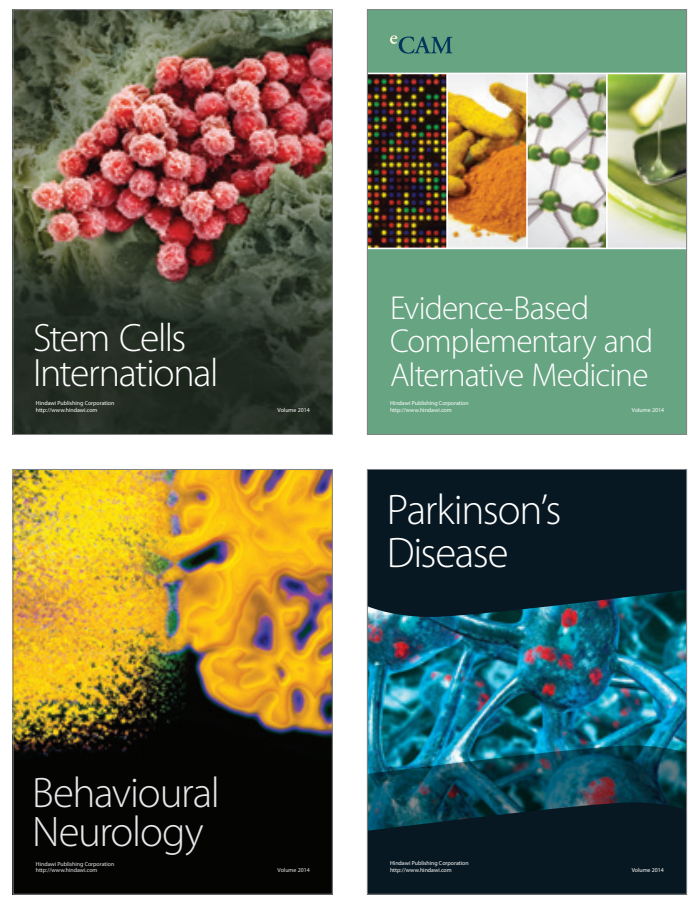
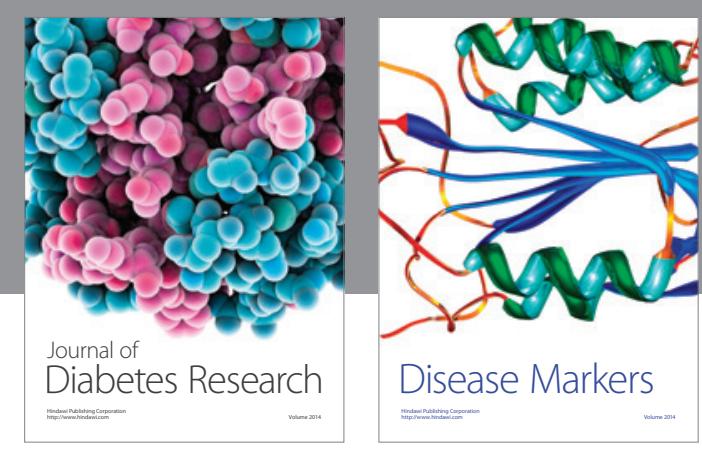

Disease Markers
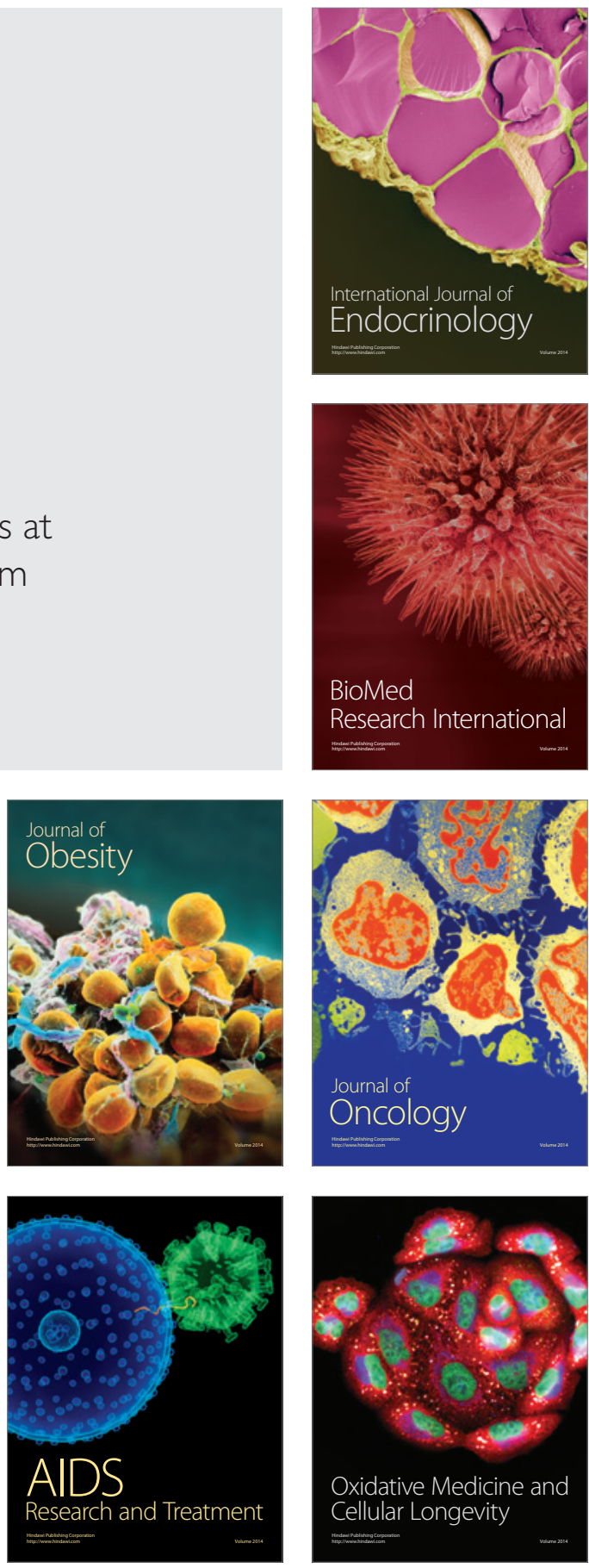